\title{
ДИСТАНЦИОННОЕ ОБУЧЕНИЕ: СОВРЕМЕННЫЕ РЕАЛИИ
}

\section{REMOTE LEARNING: MODERN REALITIES}

I. Skorobach

Summary: The article reveals the current state of e-learning and distance education in modern Russia, taking into account the existing coronavirus pandemic, the positive aspects of such education and its shortcomings. The main reasons for the unsatisfactory state of distance education in our country are considered.

Keywords: e-learning, distance education.
Скоробач Ирина Робертовна

К.п.н., дочент, ФГБОУ ВО «Сахалинский государственный университет»

skorobachirina@gmail.com

Аннотация: Статья раскрывает современное состояние электронного обучения и дистанционного образования в современной России сучетом имеющей место пандемии коронавируса, положительные стороны такого образования и его недостатки. Рассматриваются основные причины неудовлетворительного состояния дистанционного образования в нашей стране.

Ключевые слова: электронное обучение, дистанционное образование.
$\mathrm{H}$ епростые времена переживает общество сейчас. И причин тому много. Главная - постоянно изменяющаяся картина мира, стремительное развитие всех сфер жизнедеятельности человека.

Вторая причина - это обилие информации, которая совсем неоднозначна, а так же, связанное с этим, быстро меняющееся информационное пространство.

Трудности, связанные с тем, как поспевать за всем новым, нетрадиционным, но необходимым для того, чтобы идти в ногу со временем, с переменами и вписываться в это новое состояние жизни, заставляют нас предпринимать самые различные шаги, способствующие успешному движению вперед.

Основным направлением в решении обозначенных трудностей должно стать принципиально иное отношение общества к образованию, его построению, организации и достижению целей, отвечающих потребностям развития человека и общества в целом.

Петькова Ю. Р. обращает внимание на то, что «В современном глобальном информационном мире наблюдается тенденция к исчезновению грани между традиционным образованием и дистанционным, т.к большинство людей в процессе обучения прибегает к Интернету. В настоящее время в Интернете можно найти абсолютно любую интересующую тему, такое явление облегчает поиск информации и сокращает время»[3].

Она в статье отмечает преимущества и недостатки дистанционного образования и, что вопрос о будущем дистанционного образования все еще остается дискуссионным, т.к. у него много проблем.

Вопросами дистанционного обучения в нашей стране ученые занимаются давно (С.А. Щенников, Е.С. Полат, А.В. Хуторской и др.) Попыткой решения проблем обра- зования в новых условиях стало введение дистанционного обучения. По этому поводу уже написана масса статей и научных трудов. Однако, мы споткнулись на самом простом, но уж очень характерном для нас, россиян, на принципе (если это можно назвать принципом) - начинаем что-то делать, «когда рак на горе свистнет». И вот он «свистнул». Какая-то мелюзга в виде коронавируса подловила нас на нашей же «коронной» установке. И в какой же это уже раз нас подводит она? Очень больно это проявилось в нашей системе образования.

Необходимость ограничения контактов с людьми (привычным для нас окружением), невозможность реализации обычных жизненных задач прежними способами поставили на первый план переход на дистанционное общение, как единственно отвечающее современному состоянию общества.

Ушло понимание полученного образования как навсегда данного, достаточного на всю жизнь. Человек столкнулся с проблемой, что уже не может довольствоваться полученным образованием. Теперь он вынужден развивать себя с учетом требований времени, учиться постоянно и непрерывно, чтобы быть востребованным и конкурентно способным на рынке труда. Это уже понимают все. Но действительность показывает, что не каждый готов это принять, т.к. это требует переломить, изменить себя. А это дается нелегко, особенно старшему поколению. Но здесь основной задачей государства и общества является - помочь таким людям вписаться в новые реалии, ощутить свои силы и возможности в преодолении неготовности осуществлять жизнь по-новому.

О дистанционном образовании и электронном обучении говорится в главном документе нашей страны по образованию Ф3 №273 «Об образовании в РФ», а ему уже почти тридцать лет, он все время совершенствуется, исходя из меняющейся ситуации в стране и мире. В нем показано, как нам предстоит работать в ближайшее 
время. Так, например, в статье 13 и 16 отмечается что образовательная деятельность может осуществляться «как самостоятельно, так и посредством сетевых форм...», «При реализации образовательных программ используются различные образовательные технологии, в том числе дистанционные образовательные технологии, электронное обучение». А далее в Законе раскрывается суть электронного обучения и его дистанционных форм, показано как следует это осуществлять. [1]

Но в чем же проблема, что продвинулись мы в этом направлении очень незначительно, не считая специалистов в области информационных технологий? А ответ и здесь тот же - образование все еще топчется на месте.

Работать удаленно - это требование. Но как это выполнить? Практика показала, что миллионы людей в нашей стране оказались не готовыми к этому. Застряла школа, как общеобразовательная, так и, отчасти, профессиональная, в том числе высшая. Это особенно ощутилось в период пандемии коронавируса. Весь процесс обучения проходит в системе MOODLE - Modular ObjectOriented Dynamic Learning Environment (модульная объектно-ориентированная динамическая обучающая среда). Эта система позволяет преподавателям создавать свои авторские курсы, разрабатывать задания и оценивать их, прикреплять ссылки, загружать видеоуроки, проводить консультации и прочее. Но почему это проходит с пробуксовками? Почему это проявилось в срыве полноценного образовательного процесса? Отчего невозможным оказалось дистанционное обучение? Некоторые причины можно сформулировать так:

1. неподготовленность педагогических кадров к осуществлению такого образования;

2. отсутствие разработанных образовательными учреждениями программ дистанционного образования;

3. невозможность обучения по ряду дисциплин или отдельных разделов, тем курсов;

4. слабая обеспеченность техническими средствами (компьютерами, планшетами, интернет-связью) обучающих и обучающихся;

5. недостаточное финансирование процесса дистанционного образования;

6. отсутствие необходимых условий для реализации электронного обучения и осуществление его в дистанционной форме;

7. психологическое неприятие подобных новшеств;

8. отсутствие контроля со стороны управленческих структур.

Дистанционное обучение имеет свои плюсы, которые помогают выплывать в сложившейся обстановке. Оно гарантирует нам, что будет спасать нас всегда, когда потребуется, и мы сможем таким образом двигаться дальше и существовать. Каковы же преимущества дистанционной формы обучения? Отметим некоторые из них:

1. Возможность проходить обучение, не покидая места жительства и в процессе производственной деятельности.

2. Широкий доступ к образовательным ресурсам.

3. Возможность получить образование при любом уровне подготовки.

4. Возможность организации процесса самообучения в наиболее приемлемой для каждого форме.

5. Возможность прерывания и продолжения образования в зависимости от индивидуальных возможностей и потребностей.

6. Снижение стоимости обучения за счёт широкой доступности к образовательным ресурсам.

7. Формирование уникальных образовательных программ за счет комбинирования курсов, предоставляемых образовательными учреждениями.

8. Повышение активности и заинтересованности обучающихся в получении образования.

9. Возможность создать условия для реализации индивидуальной образовательной траектории и персонализации обучения.

10. Повышение качества обучения за счет применения средств современных информационных и коммуникационных технологий.

11. Открытый доступ к различным информационным ресурсам для образовательного процесса в любое удобное для обучающегося время.

12. Созданию единой образовательной среды Школы.

13. Повышению эффективности учебной деятельности, интенсификации самостоятельной работы обучающихся.

14. Повышению эффективности организации учебного процесса.

15. Удовлетворение потребности страны в качественно подготовленных специалистах и квалифицированных рабочих.

Безусловно, электронное обучение и дистанционная его форма имеют и недостатки, но их меньше, нежели преимуществ. Следует сказать о них. Это:

- отсутствие прямого контакта субъектов обучения;

- невозможность почувствовать настроение и эмоциональное состояние сторон - участников образовательного процесса;

- сложности в осуществлении проверки продвижения в обучении;

- проблемы с обучением слабоуспевающих студентов.

Можно назвать и другие недостатки. Например, Гаус И.В. отмечает: «Серьезной проблемой является психологическая адаптация к ДО при отсутствии личного контакта обучающегося с педагогом, а также отсутствие навыков самоорганизации. Среди минусов ДО стоит отметить ухудшение устной речи у обучающегося и снижение коммуникационной культуры в развитии личности». [2] 
В связи с коронавирусом все недостатки выявились очень наглядно. Помимо отмеченного, нужно констатировать, что многих участников образовательного процесса это застало врасплох. Они не ожидали такого поворота событий. Все стало делаться в последний момент в ситуации неподготовленности и неопределенности.
Подводя итог, можно сказать, что необходимо серьезно и комплексно подойти к вопросу дистанционного образования, с учетом всех его преимуществ и недостатков. Нужно срочно взять это на контроль, сделать одним из приоритетных направлений развития современного образования и тогда это даст желаемые результаты.

\section{ЛИТЕРАТУРА}

1. Федеральный закон РФ «06 образовании Российской Федерации», N 273-ФЗ, глава 1, ст. 13,16 с изменениями и дополнениями 0т 19.09.2019.

2. Гаус Ирина Васильевна. Организация дистанционного обучения в образовательном учреждении. https://infourok.ru/statya-organizaciya-distancionnogoobucheniya-vobrazovatelnom-uchrezhdenii3740003.html

3. Петькова Ю.Р. «История развития дистанционного образования. Положительные и отрицательные стороны М0ОС» [Электронный ресурс]. - Режим доступа: https://www.elibrary.ru/item.asp?id=23945311 (Дата обращения: 02.02.2020).

$$
\text { (c) Скоробач Ирина Робертовна (skorobachirina@gmail.com). }
$$

Журнал «Современная наука: актуальные проблемы теории и практики»

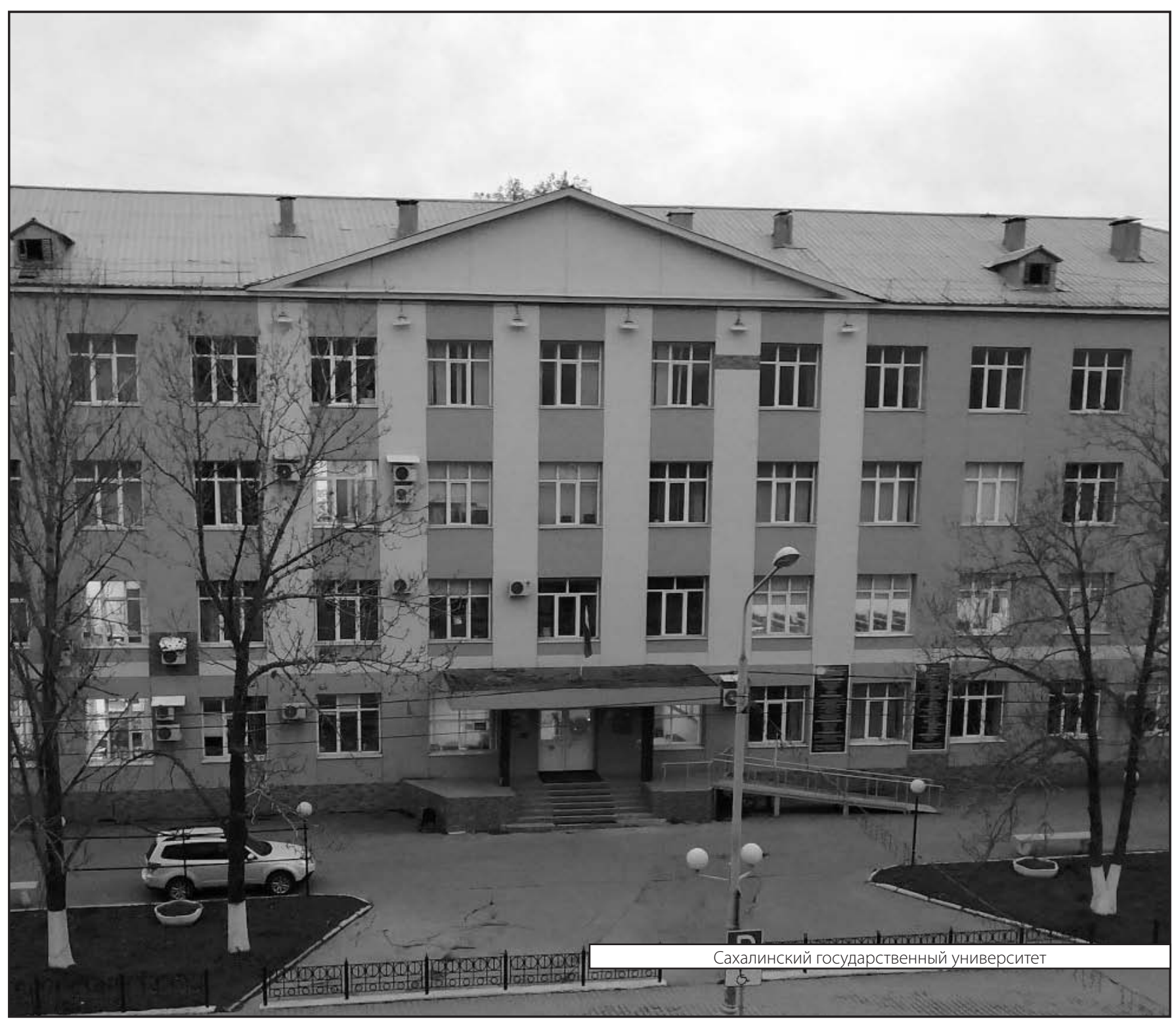

